*Professor do Programa de Pósgraduação em Direito da UNIMAR - Mestrado e Doutorado. Doutor e Mestre em Direito Econômico pela Universidade Federal da Paraíba (UFPB).

E-mail: bbastos.adv@gmail.com

$* *$ Mestre em Direito na
Universidade (UNIMAR). Pós graduado em finanças, investimentos e banking pela PUC do Rio Grande do Sul- PUCRS, pós graduado em direito ambiental com qualificação para o exercício do magistério superior pela Escola Superior da Procuradoria Geral do Estado ESPGE e pós graduado em direito privado pela Universidade para o desenvolvimento do Estado e da Região do Pantanal - UNIDERP.

E-mail: richardbassan@adv.oabsp. org.br

***Doutoranda em Direito na Universidade de Marília (UNIMAR).

E-mail: criscantidio@hotmail.com

\section{A Busca Pela Eficiência No Âmbito Das Execuções Fiscais Municipais E A Transação Tributária}

\author{
The Search For EfFiciency Within Local TaX \\ IMPLEMENTATION AND TAX TRANSACTION
}

\section{Bruno Bastos de Oliveira* Richard Bassan** Cristiana Carlos do Amaral Cantídio***}

Como citar: OLIVEIRA, Bruno Bastos de; BASSAN, Richard; CANTÍDIO, Cristiana Carlos do Amaral. A busca pela eficiência no âmbito das execuções fiscais municipais a a transação tributária. Revista do Direito Público, Londrina, v. 16, n. 3, p. 83-100, dez. 2021. DOI: 10.5433/24157-108104-1.2021v16n 3p.83. ISSN: $1980-511 \mathrm{X}$

Resumo: Discute-se a utilização do instituto da transação em matéria tributária como meio adequado para a eficiência arrecadatória no âmbito das execuções fiscais municipais e a consequente desobstrução do Judiciário brasileiro. A problematização repousa na demora da reintegração dos créditos tributários pelos métodos usuais aplicados nos processos executivos e a obstrução que o volume de demandas causa no âmbito do Judiciário. O problema apresentado será enfrentando a partir da análise da originalidade e legitimidade social tributária, a forma de gestão do tributo com vistas à otimização das relações entre o contribuinte e o fisco, assim como a aplicabilidade da transação tributária como forma adequada de solução de conflitos e controvérsias no âmbito fiscal. Utilizando-se de pesquisa exploratória, bibliográfica, qualitativa e quantitativa, o objeto de investigação reside na análise dos aspectos legais acerca da transação tributária, os princípios norteadores do processo fiscal administrativo fazendário, enfatizando-se a atuação legislativa e executiva no plano municipal. Conclui-se que a transação tributária mostra-se como adequação na eficiência do cobrança, aumento da arrecadação e consequente desobstrução do Judiciário brasileiro.

Palavras-chave: Direito Tributário; Transação tributária; Execução fiscal; Contribuinte; Município.

Abstract: We discuss the use of the transaction institute in tax matters as a suitable means for efficient collection in the scope of municipal tax executions and the consequent unblocking of the Brazilian Judiciary. The problem lies in the delay in the reinstatement of tax credits by the usual methods applied in 
the executive processes and the obstruction that the volume of claims causes to the Judiciary. The problem will be faced from the analysis of the originality and social legitimacy of the tax, the form of tax management with a view to optimizing relations between the taxpayer and the tax authorities, as well as the applicability of the tax transaction as an appropriate way to solve conflicts and controversies in the tax field. Using an exploratory, bibliographical, qualitative and quantitative research, the object of the investigation lies in the analysis of the legal aspects of the tax transaction, the guiding principles of the tax administrative process, emphasizing the legislative and executive action at the municipal level. It is concluded that the tax transaction shows itself as an adequacy in the efficiency of the collection, increase in revenue and consequent unobstructing of the Brazilian Judiciary.

Keywords: Tax Law; Tax Transaction; Tax Enforcement; Taxpayer; Municipality. 


\section{INTRODUÇÃO}

Verifica-se, na esfera do Direito Tributário brasileiro contemporâneo, instituto relevante e polêmico, a transação em matéria tributária. O ponto crucial dos embates sobre a temática é a possibilidade, por meio de acordo entre partes, de alcançar a extinção de demandas entre o contribuinte e os Fiscos. As inovações trazidas pelo instituto da transação têm ganhado espaço, tornando-se objeto de Projeto de Lei Geral de Transação em matéria tributária que tramita no Congresso Nacional, projeto de Lei $\mathrm{n}^{\circ}$ 5.082/2009.

O presente artigo busca estudar o instituto da transação em matéria tributária como um meio adequado para a eficiência arrecadatória no âmbito das execuções fiscais, em especial no âmbito municipal, e consequente desobstrução do Judiciário brasileiro.

Entende-se que a temática envolvendo o instituto da transação tributária está permeada por fatores intrínsecos e extrínsecos que norteiam sua necessidade, fatores esses como a superlotação de processos executivos fiscais no âmbito do Poder Judiciário e, a falta de efetividade e celeridade na apreciação dos mesmos. Neste cenário, o aspecto da celeridade judicial constitui-se um dos maiores desafios e preocupações atuais na seara do Direito Tributário.

Urge a necessidade de aplicação e implementação de métodos adequados para dirimir e solucionar as controvérsias na esfera dos conflitos fiscais, métodos esses como, a mediação em âmbito tributário, a conciliação de conflitos, a arbitragem tributária e a transação tributária, este último objeto do presente estudo. Busca-se compreender através deste instituto as nuances, com vistas a entender a relação que se estabelece entre o contribuinte e o fisco e sua contribuição como meio adequado para a eficiência arrecadatória no âmbito das execuções fiscais.

O estudo da transação em matéria tributária é imprescindível para a compreensão do cenário contemporâneo das execuções fiscais tributárias e as relações que se estabelecem entre fisco e contribuinte.

Para delimitar e apresentar com eficiência e clareza os objetivos e resultados do presente artigo de pesquisa, estrutura-se em cinco tópicos, sendo no primeiro a estrutura atual das execuções fiscais, no segundo o déficit de arrecadação e ineficiência nos municípios, no terceiro a estrutura do Poder Judiciário e alta litigiosidade fiscal, no quarto a análise dos números do Conselho Nacional de Justiça (CNJ) sobre os processos fiscais e no quinto e último o instituto da transação em matéria tributária como meio legal em busca da eficiência arrecadatória no plano municipal e consequente desobstrução do Poder Judiciário.

Utilizando-se de pesquisa exploratória, bibliográfica, qualitativa e quantitativa, os capítulos aqui apresentados contemplam as principais indagações exploradas no decorrer do estudo permitindo-se, com o desfecho, a confirmação da hipótese no que tange a possibilidade do instituto da transação em matéria tributária ser meio adequado para a eficiência arrecadatória no âmbito das execuções fiscais municipais. 


\section{ESTRUTURA ATUAL DAS EXECUÇÕES FISCAIS}

A estruturação atual dos processos de execuções fiscais no Brasil apresenta nítida ineficácia, ou seja, nota-se imensa lentidão no decurso processual, que ocorre devido ao grande e oneroso investimento público na tentativa de resgatar os ativos fiscais. Percebe-se a falta de veracidade na equidade entre os indivíduos inseridos nos processos judiciais de cunho fiscal, ou seja, tal realidade se concretiza devido às vantagens que a legislação fiscal delega à Fazenda Pública, contudo, mesmo com inúmeros privilégios inerentes à Fazenda Pública, ainda assim, os processos de execuções fiscais necessitam de celeridade e efetividade (CUNHA, 2016, p. 27).

Denota-se que o poder executivo quando emite título executivo próprio e simplificado - Certidão de Dívida Ativa; coloca-se em significativa superioridade em detrimento ao sujeito passivo da execução, como exemplo a não demonstração de cálculos uniformes com informações precisas, diferenciando-se dos títulos executivos da esfera civil (SCHERER, 2015, p. 2).

A certidão de dívida ativa representa uma obrigação líquida, certa e exigível, créditos esses definidos na forma da lei. Portanto, quando ocorre a inscrição o crédito anteriormente exigível torna-se título exequível, caracterizando uma diferenciação da condição inicial do título. Referida certidão, portanto, é um título de caráter formal, cuja formalização do título de crédito se dá pela ação do poder público de maneira unilateral, desta forma, fundamenta e apresenta os elementos principais, faz a atualização monetária, a correção de juros, das multas, mora e outros encargos devidos (CUNHA, 2016, p. 29).

Sobre a ineficiência na cobrança da dívida ativa destaca-se o ensinamento do doutrinador Gustavo Caldas Guimarães de Campos (2019, p. 73):

\footnotetext{
A ineficiência na cobrança da dívida ativa ocorre em virtude da baixa qualidade do bem penhorado, a ausência total de garantias ou até mesmo a falta de informação confiável sobre o patrimônio do devedor. No que se refere à substituição de bens ofertados garantidores da execução, a critério do poder público pode o executado, a qualquer momento, ser instado a realizar a troca do bem, ao passo que, o mesmo benefício não é disponível ao devedor, fazendo apenas passar pelo crivo fazendário.
}

À Fazenda Pública ainda é atribuída a utilização de medidas antecipadas de créditos realocados na ação de execução, o que ocorre com o intuito de se resguardar de possíveis danos, como o desvio de personalidade jurídica ou abuso de poder, como também salvaguardar e abranger os grupos econômicos que respondem solidariamente pelo débito de característica funcional. Observa-se, portanto, a existência de alegações tendenciosas, advindas do Poder Executivo, argumentos, esses, que justificam transformar a execução fiscal em um padrão expropriatório administrativo (SCHERER, 2015, p. 3).

Corrobora-se que apesar das tentativas aplicadas para mudar a forma como a execução fiscal vem sendo administrada na atualidade, na tentativa de torná-la mais eficiente, restam claras as dificuldades que o Poder Judiciário vem administrando em decorrência do gradativo aumento 
das execuções fiscais não concluídas, tentativas infrutíferas de localizar o legítimo devedor, os bens levados a penhora e, também, devido às inúmeras ocorrências de desconstituições irregulares de empresas, as insolvências civis, entre outras limitações.

Neste contexto, importante se faz o entendimento de José Renato Nalini (2019, p. 1):

Todos os anos o Governo, suas Autarquias e Fundações - aí compreendidas União, Estados e Municípios - arremessam à Justiça milhões de CDAs - Certidões de Dívida Ativa, que darão origem a execuções fiscais. O Judiciário se conforma com a situação esdrúxula. Aceita ser cobrador de dívida. Mesmo sabendo que não tem estrutura, pessoal nem gestão eficiente para fazer funcionar um setor nevrálgico. Todos têm interesse em que os devedores recolham ao Erário o devido. Se eles se recusarem a pagar, o ônus de sustentar a máquina - sempre perdulária e quase sempre ineficiente - recairá sobre os demais.

Nota-se, portanto, um cenário obscuro nas execuções fiscais no Brasil, com acúmulo de processos nas varas responsáveis, falta de infraestrutura, como recursos de pessoal, materiais, entre outras ferramentas tecnológicas que impedem o atendimento dos processos demandados, sendo as circunstancias mencionadas grande óbice enfrentado para satisfazer os créditos públicos. Acentua-se ainda a questão das prescrições fiscais preconizadas na legislação tributária que se tornam obstáculos importantes ao sistema de créditos em geral (SCHERER, 2015, p. 3).

Com efeito, percebe-se que a execução fiscal enfrenta relevantes prejuízos que são absorvidos não apenas pelo ente tributante, mas também pelo Poder Judiciário e pelos próprios contribuintes. Portanto, diante do cenário apresentado no tópico em comento, passa-se a analisar na sequência os déficits arrecadatórios e ineficiência nos municípios.

\section{DÉFICIT DE ARRECADAÇÃO E INEFICIÊNCIA NOS MUNICÍPIOS}

A administração tributária está organizada conforme disciplina a Constituição Federativa do Brasil de 1988, distribuído funções e competências aos Estados da federação por meio de suas Constituições Estaduais e aos Municípios por meio de sua Lei Orgânica. Portanto, esta estrutura constitucional permite que cada esfera governamental organize sua administração de forma independente, como na esfera federal tem-se o Ministério da Fazenda e a Receita Federal, na estadual a Secretaria da Fazenda e nos municípios, as Secretarias de Finanças (BRASIL, 1988).

O papel do município na administração pública brasileira está relacionado a atender as peculiaridades que envolvem o poder local e, com o advento da Constituição Federal de 1988, tornou-se unidade política dotada de autonomia para gerir os as demandas e serviços públicos dentro de sua jurisdição. Neste encadeamento, verifica-se a denominada descentralização do poder público administrativo, o que proporcionou aos municípios mudanças significativas em suas contas, ou seja, a majoração da participação municipal na arrecadação da tributação nacional, passando ainda os municípios a assumirem a incumbência da garantia dos serviços básicos destinados à 
sociedade local, como saúde, educação, habitação e assistência social, entre outras (BRASIL, 2019).

Revela-se que as novas prerrogativas atribuídas aos municípios culminaram com o aumento de despesas dos mesmos. Vale ressaltar que os municípios não estavam condicionados a esforços com vistas ao aumento da eficácia arrecadatória de tributos e com as consequentes despesas que passaram a crescer. Dentro do cenário apresentado os municípios passaram a gastar suas receitas em volumes mais elevados comparados com suas arrecadações. Portanto, o comportamento apresentado desencadeou o aumento de dívidas, ocasionando escassez nas finanças e descontrole no orçamento fiscal.

Em detrimento das dificuldades apresentadas e com o intuito de diminuir o déficit público e conter as finanças dos municípios, a União promulgou a Lei de Responsabilidade Fiscal - LRF; introduzindo normas para conduzir as tomadas de decisões dos entes públicos, normas essas norteadoras para o cumprimento de preceitos legais para a devida condução dos recursos públicos (CAMPELLO; MATIAS, 2014, p. 413).

Compreende-se que os fundamentos que norteiam a Lei de Responsabilidade Fiscal - LRF; objetivam ajudar o administrador municipal a equilibrar permanentemente suas contas públicas, possibilitando a organização orçamentária de forma sensata, com o devido respeito ao princípio orçamentário do equilíbrio, com vistas a garantir recursos para financiar todo o aparato administrativo garantindo, assim o desenvolvimento dos programas sociais voltados a garantir as necessidades básicas do cidadão (BRASIL, 2019).

Evidencia-se que os municípios brasileiros se encontram com elevado déficit de arrecadação fiscal, observando-se, ainda um aumento significativo da dependência municipal relacionado a recursos de advindos de outros entes governamentais para promoção de suas políticas públicas. Ou seja, os meios e estratégias de arrecadação tributária se mostram insuficientes em grande parte dos municípios que, ainda possuem elevada carga tributária, gastos imensos com despesas de pessoal, entre outras, que impossibilitam os municípios honrarem seus compromissos em curto prazo (BOLFE; SOUZA, 2019, p. 6).

Frisa-se sobre esta temática os ensinamentos de Zuccolotto, Ribeiro e Abrantes (2019, p. 13):

O comprometimento dos recursos públicos é, em maioria das vezes, creditado à má gestão. Os prefeitos não se utilizam do planejamento, as peças orçamentárias quase sempre representam apenas procedimentos formais e legais. Como as despesas apresentam um crescimento muito superior ao das receitas, os municípios geralmente apresentam déficits. Uma alternativa para solucionar este problema é expandir seu potencial de arrecadação para que não fiquem tão dependentes de outras esferas de governo. Expandir sua arrecadação não quer dizer aumentar a carga tributária onerando o bolso do contribuinte e sim melhorar os seus mecanismos de arrecadação. Assim, os municípios promoverão seu ajuste fiscal e poderão financiar suas políticas municipais com autonomia financeira. 
Constata-se na atualidade que a problemática fiscal existente nas contas públicas no Brasil vem se acentuando demasiadamente, devido ao número crescente das dívidas públicas dos municípios, esse aumento do déficit no orçamento advém das disparidades existentes entre as receitas e as despesas dos Municípios. Portanto, o déficit do setor público municipal reflete seu entrave estrutural, permeado pelas dificuldades criadas pela administração pública em decorrência do acúmulo dos desequilíbrios fiscais produzidos no decorrer dos anos como resultado do endividamento público dos municípios (ALVES, 2017, p. 55).

No contexto contemporâneo da estrutura tributária brasileira municipal, há uma base de tributos altamente regressiva, ou seja, grande parte dos tributos arrecadados tem seu alicerce fiscal recaindo sobre a circulação de bens e consumo, gerando consequentemente encargos que são repassados aos consumidores e contribuintes (ALBUQUERQUE, 2016, p. 32).

Com relação ao tema importante se faz sobrelevar os ensinamentos de Cunha Junior et al (2019, p. 1):

Para sair dessa situação e criar espaço fiscal para realizar investimentos, as Administrações Públicas Municipais precisam adotar medidas para ampliar a arrecadação, reduzir despesas e melhorar a qualidade e a eficiência do gasto público, evitando-se, contudo, majorar ou criar tributos e contribuições ou cortar programas públicos de grande impacto social por meio da vinculação de receitas e despesa pública no estabelecimento dos mínimos constitucionais

Ultima-se neste encadeamento com o entendimento de que a administração pública municipal carece urgentemente controlar sua base fiscal, afigurando-se que tal postura envolve melhorias na racionalização dos procedimentos de recolhimento dos seus tributos, como por exemplo, o instituto da transação, visando-se a busca pela eficiência tributária e consequentemente a recuperação e o aumento da arrecadação.

A partir da problemática até aqui analisada, passa-se ao estudo da estruturação do Poder Judiciário e a alta litigiosidade fiscal.

\section{ESTRUTURA DO PODER JUDICIÁRIO E ALTA LITIGIOSIDADE FISCAL: UMA ANÁLISE A PARTIR DOS NÚMEROS DO CNJ}

A estruturação do Poder Judiciário está disciplinada na Carta Magna do Brasil de 1988, atribuindo aos tribunais o poder de eleger os órgãos diretivos sob sua administração, elaborando seus regimentos internos, organizando suas secretarias, serviços auxiliares e os juízos subordinados a sua jurisdição, na criação e administração de cargos da magistratura e respectiva carreira, assim como, prover todas as necessidades referentes à administração da Justiça, entre outras (BRASIL, 2019).

Entende-se que para a efetivação do princípio da proteção judicial de forma concreta há a 
implicação da justiça aplicada de forma eficiente e célere, esse entendimento relaciona-se com os preceitos de acesso à justiça, preconizados na Carta Magna do Brasil de 1988; com a introdução do inciso LXXVII, do artigo $5^{\circ}$; efetuada por meio da Emenda Constitucional $n^{\circ}$ 45, de 2004; que instituiu a Reforma do Judiciário, a saber: "a todos, no âmbito judicial e administrativo, são assegurados a razoável duração do processo e os meios que garantam a celeridade de sua tramitação" (BRASIL, 2019).

Ademais, o acesso à justiça se relaciona efetivamente com a consolidação do princípio constitucional da dignidade da pessoa humana. Mas não basta somente a possibilidade de buscar o Judiciário, mas sim à efetiva recepção de uma solução ao conflito. Nesse sentido Daiane Schwabe Minelli e Sergio Alves Gomes (2019, p. 151) mencionam:

O caminho para a consolidação do princípio constitucional da dignidade da pessoa humana passa, principalmente, pelo efetivo acesso à justiça, que possa proporcionar a concretização dos direitos fundamentais que integram aquele núcleo mínimo de existência digna de todos os seres humanos.

O primeiro grau de jurisdição da Justiça Federal encontra-se estruturado conforme preceitua a Lei n. 5.010, de 30 de maio de 1966; disciplinando que no Distrito Federal e em cada Estado da Federação será instituída uma seção judiciária. Contudo, cada seção, constituída por varas federais, terá suas sedes nas unidades federativas, ou seja, em suas capitais, na falta, portanto, de varas federais nas respectivas comarcas fica a cargo dos juízes estaduais a competência para apreciar e julgar os processos a eles correspondentes. Entretanto, nas varas federais, seus juízes federais atuaram processaram e julgaram a maioria dos processos e ações de responsabilidade da Justiça Federal (BRASIL, 1966).

O primeiro grau do Poder Judiciário está estruturado em 15.398 unidades judiciárias - um aumento de 20 unidades em relação ao ano anterior. Esse quantitativo é subdividido em 10.989 varas estaduais, trabalhistas e federais $(71 \%) ; 1.606$ (10,4\%) juizados especiais; 2.771 (18\%) zonas eleitorais; 13 auditorias militares estaduais; e 19 auditorias militares da União. A maioria das unidades judiciárias pertence à Justiça Estadual, que possui 10.035 varas e juizados especiais e 2.697 comarcas (48,4\% dos municípios brasileiros são sede da Justiça Estadual). A Justiça do Trabalho está sediada em 624 municípios (11,2\% dos municípios) e a Justiça Federal em 279 (5\% dos municípios) (CONSELHO NACIONAL DE JUSTIÇA, 2018, p. 18).

Repara-se que os Tribunais Superiores brasileiros constituem-se órgãos supremos das esferas judiciárias, atuam em processos de competência originária, como também, efetuam as revisões das ações decididas nas instâncias de $1^{\circ}$ ou $2^{\circ}$ graus. Importante frisar que a atuação é realizada por colegiados, ou seja, por magistrados intitulados Ministros. Os Tribunais Superiores do Brasil são os seguintes: Superior Tribunal de Justiça - STJ, Superior Tribunal Militar - STM, Tribunal Superior Eleitoral - TSE e o Tribunal Superior do Trabalho - TST (CONSELHO 
NACIONAL DE JUSTIÇA, 2018, p. 16).

O Poder Judiciário contava com um acervo de 80,1 milhões de processos pendentes de baixa no final do ano de 2017, sendo que mais da metade desses processos $(53 \%)$ se referia à fase de execução. Os dados mostram que, apesar de ingressar no Poder Judiciário duas vezes mais casos em conhecimento do que em execução, no acervo, a execução é 34,6\% maior. Na execução, as curvas de processos baixados e novos seguem quase paralelas durante os nove anos da série histórica. Já no conhecimento, as curvas se mantiveram semelhantes até 2014, com um descolamento a partir de 2015. Os casos pendentes na fase de execução apresentam aumentos regulares, numa clara tendência de crescimento do estoque. Já os casos pendentes na fase de conhecimento oscilam mais, tendo havido incremento do estoque em 2015 e 2016, e queda em 2017 (CONSELHO NACIONAL DE JUSTIÇA, 2018, p. 120).

Observa-se que é neste ambiente que o sistema de tributação brasileiro contemporâneo, especialmente no plano municipal, traz carga excessiva ao Poder Judiciário, o que se evidencia segundo dados apresentados pelo CNJ; apresentado em seu Relatório Justiça em Números 2018, incluindo-se os dados dos processos de execuções fiscais. Com efeito, a alta litigiosidade verificada nos números, as ações tributárias intermináveis, trazem consequências desastrosas para o crescimento da economia brasileira, o que incentiva a sonegação fiscal, a exclusão, o crescimento do desemprego e o consequente aumento do déficit previdenciário.

Em razão desta contextura, imprescindível se faz a análise dos números do CNJ; relacionados aos processos de execução fiscal, o que se fará no tópico a seguir.

Importante salientar a institucionalização do $\mathrm{CNJ}$; por meio da Emenda Constitucional

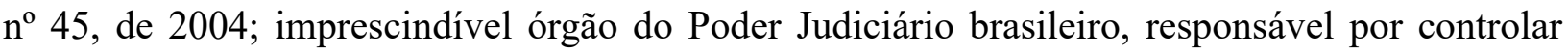
e supervisionar administrativamente e financeiramente as atuações do Poder Judiciário, fazendo parte se sua composição magistrados, representantes da advocacia e da sociedade civil, integrantes do Ministério Público, entre outros (BRASIL, 2019).

Ressalta-se que o CNJ; juntamente com o Instituto de Pesquisa Econômica Aplicada IPEA; com o intuito de aprimorar os processos de cobranças da dívida ativa fiscal, estabeleceram parceria buscando a mensuração das execuções fiscais anualmente processadas no país, tal intento, advém por meio de projeto de pesquisa, com apresentação de relatório anual, tendo como premissa dimensionar de forma efetiva as relações de tempo e custo relacionados aos trâmites dos processos de execução fiscal junto ao Poder Judiciário Nacional.

Os indicadores apresentados nesta edição do Relatório Justiça em Números sumarizam os principais resultados alcançados pelo Poder Judiciário em 2017, possibilitando a identificação de avanços, como o aumento do volume de processos decididos (baixados) e a redução do estoque processual na fase de conhecimento, assim como dos gargalos que permanecem, a exemplo da morosidade na fase de execução (CONSELHO NACIONAL DE JUSTIÇA, 2018, p. 198). 
Vislumbra-se, segundo os dados do relatório Justiça em Números 2018: ano-base 2017 do CNJ, durante o ano de 2017; estavam em trâmite no judiciário brasileiro 80,1 milhões de processos pendentes de baixa no final do ano em análise, contudo, mais da metade desses processos, ou seja, (53\%) refere-se à fase de execução. A pesquisa retrata dados estatísticos que evidenciam as ações que ingressaram no Poder Judiciário, ocorrendo duas vezes mais ações na fase de conhecimento do que na de execução, contudo, as ações na fase de execução são 34,6\% maiores (CONSELHO NACIONAL DE JUSTIÇA, 2018, p. 120). Nesta conexão, frisam-se os números estatísticos do relatório do $\mathrm{CNJ}$ :

A maior parte dos processos de execução é composta pelas execuções fiscais, que representam $74 \%$ do estoque em execução. Esses processos são os principais responsáveis pela alta taxa de congestionamento do Poder Judiciário, representando aproximadamente $39 \%$ do total de casos pendentes, e congestionamento de $92 \%$ em 2017 - a maior taxa entre os tipos de processos constantes nesse Relatório. O impacto da execução é significativo principalmente nos segmentos da Justiça Estadual e Federal, correspondendo, respectivamente, a $55 \%$, 50\%, e $44 \%$ do acervo total de cada ramo.

Corrobora-se com a premissa de que, a fase de execução chega a absorver mais de $60 \%$ do acervo processual. Observa-se que os índices na fase de execução são superiores a fase de conhecimento na maioria dos casos. Portanto, ao se verificar os índices de congestionamento no conhecimento e na execução no $1^{\circ}$ grau, se tem as taxas na execução fiscal são maiores em quantidade (CONSELHO NACIONAL DE JUSTIÇA, 2018, p. 121, 125).

Importante a análise da tabela abaixo para a confirmação dos dados anteriormente aferidos, a saber:

\begin{tabular}{|c|c|}
\hline Clabuticacso & $\begin{array}{c}\text { Taride } \\
\text { Cocosursosamento }\end{array}$ \\
\hline Sonhecinaese Crienied & 7300 \\
\hline Donhecinerro Nlo-Crinhal & $005 \%$ \\
\hline Total Connecinerts & 5255 \\
\hline Enecuplo Fiveal & $91,7 \%$ \\
\hline 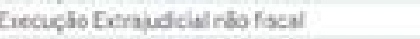 & as chis \\
\hline tecucle dufeal Na-Crinind & $72 \pi$ \\
\hline Enecuc So Punal Rise-Privaliva de Lberdade & $57,6 \mathrm{~s}$ \\
\hline 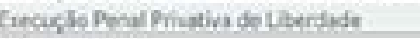 & $895 x$ \\
\hline folat toecusbe & $35, a \mathrm{~A}$ \\
\hline atal Geal & 72.15 \\
\hline
\end{tabular}

Fonte: Relatório Justiça em Números 2018, p. 125.

Verifica-se que no decorre da história as execuções fiscais têm sido indicadas como elemento determinante da morosidade das ações no judiciário brasileiro. Importante frisar que o as 
ações executivas fiscais vêm a juízo após inúmeros intentos de recuperação do crédito tributário, ou seja, após diversas tentativas frustradas na esfera administrativa, acarretando a inscrição em dívida ativa. Diante do exposto, o processo judicial passa a se replicar por infinitas e repetidas fases de insucessos, como providenciar a localização do devedor ou patrimônio com capacidade de atender o crédito tributário, cuja postura acarreta ao Poder Judiciário a obrigatoriedade de administrar e julgar os títulos de dívidas antigas e, consequentemente, com ínfima viabilidade de recuperá-las (CONSELHO NACIONAL DE JUSTIÇA, 2019, p. 125).

Os processos de execução fiscal representam, aproximadamente, $39 \%$ do total de casos pendentes e $74 \%$ das execuções pendentes no Poder Judiciário, com taxa de congestionamento de $91,7 \%$. Ou seja, de cada cem processos de execução fiscal que tramitaram no ano de 2017, apenas oito foram baixados. Desconsiderando esses processos, a taxa de congestionamento do Poder Judiciário cairia nove pontos percentuais, passando de $72 \%$ para $63 \%$ em 2017. O maior impacto das execuções fiscais está na Justiça Estadual, que concentra $85 \%$ dos processos. A Justiça Federal responde por 14\%; a Justiça do Trabalho, 0,31\%, e a Justiça Eleitoral apenas $0,01 \%$. A maior taxa de congestionamento de execução fiscal está na Justiça Federal (94\%), seguida da Justiça Estadual (91\%) e da Justiça do Trabalho (87\%). A menor é a da Justiça Eleitoral (74\%). O tempo de giro do acervo desses processos é de 11 anos, ou seja, mesmo que o Judiciário parasse de receber novas execuções fiscais, ainda seriam necessários 11 anos para liquidar o acervo existente. (CONSELHO NACIONAL DE JUSTIÇA, 2019, p. 125).

Do que se nota e se extrai das informações e dos resultados da pesquisa em comento auferida pelo $\mathrm{CNJ}$; sobre a realidade da morosidade na resolução das ações de execuções fiscais, mostra-se imprescindível o reexame da concepção do executivo fiscal, ou seja, torna-se imperioso a busca por melhores formas de efetivação dessas ações por meio de medidas alternativas, sendo uma delas o objeto do presente estudo, a qual será abordada abaixo.

\section{A TRANSAÇÃO TRIBUTÁRIA: MAIS QUE UMA POSSIBILIDADE, UMA NECESSIDADE}

O instituto da transação tributária encontra previsão no Projeto de Lei Geral de Transação em matéria tributária que tramita no Congresso Nacional, a saber: o Projeto de Lei $n^{\circ}$ 5.082/2009; e também está fundamentado de forma subsidiária nos artigos 840 e 850 do Código Civil de 2012 - CC, que dispõem: Art. 840. "É lícito aos interessados prevenirem ou terminarem o litígio mediante concessões mútuas"; Art. 850. "É nula a transação a respeito do litígio decidido por sentença passada em julgado, se dela não tinha ciência algum dos transatores, ou quando, por título ulteriormente descoberto, se verificar que nenhum deles tinha direito sobre o objeto da transação"; Frisa-se, ainda o disposto no artigo 171 do CTN: 
Art. 171. A lei pode facultar, nas condições que estabeleça aos sujeitos ativo e passivo da obrigação tributária celebrar transação que, mediante concessões mútuas, importe em determinação de litígio e consequente extinção de crédito tributário. Parágrafo único. A lei indicará a autoridade competente para autorizar a transação em cada caso (BRASIL, 2009).

Trata-se de uma das formas de solução de conflitos possibilitando o fim do litígio entre as partes mediante pacto bilateral e consensual mútuo. Portanto, importante salientar os ensinamentos da doutrinadora Priscila de Mendonça, (2013, p. 134), a saber: "Para que exista uma transação, necessário se faz que haja a predisposição de solução de um conflito prévio entre as partes, o que não impede haver uma demanda judicial em curso, mas que se tenha o desejo de concluí-la da melhor forma possível".

Ao se tratar de direitos relacionados ao patrimônio e sua consequente indisponibilidade, a aplicação ou a adesão ao instituto da transação tributária na esfera do Direito Público é pouco conhecida e utilizada, em detrimento da moderação tradicionalista de conceber o direito público, portanto, o Poder Público renuncia valores em acordo diante da falta de clareza e insegurança no momento da transação, ou seja, recorre o fisco a observância a Lei de Responsabilidade Fiscal LEF; referendando o ajuste de renunciar receitas. (BRASIL, 2019).

Corrobora-se com a premissa de que as formas de recuperação de créditos tributários por meio de parcelamento ocasionam a denominada obrigação parcial do crédito, sendo admitido por meio de transação tributária, contudo, o acordo em comento deve estar previsto em lei que permita sua aplicabilidade e concessão, como fundamentam os artigos 156, inciso III e 171 e parágrafo único, do Código Tributário Nacional - CTN.

Fábio Grillo (2019, p. 103) afirma que "com o marco de uma autorização legislação específica haverá a possibilidade de se cogitar o instituto da transação em matéria tributária, com requisitos e condições que concretizem a solução consensual".

Com efeito, a utilização do instituto da transação tributária possuindo o subsídio legislativo não há motivos para ser negada, mostrando-se um importante método de solução de conflitos controvérsias em âmbito tributário, ou seja, diante da inexistência de dispositivos de lei ao conceituar tributo, impedindo a aplicação da transação como meio de solucionar os litígios fiscais, frisa-se o artigo $3^{\circ}$, do CTN; a saber: Art. $3^{\circ}$ "Tributo é toda prestação pecuniária compulsória, em moeda ou cujo valor nela se possa exprimir, que não constitua sanção de ato ilícito, instituída em lei e cobrada mediante atividade administrativa plenamente vinculada" (BRASIL, 2019).

Sob a premissa argumentativa de que o instituto da transação infringiria o princípio da indisponibilidade do interesse público, a concepção de tributo elencado no Código Tributário Nacional - CTN e, ainda afetaria a legalidade tributária, há aqueles que declaram-se contrários a criação do instituto da transação. Contudo, há adeptos em contrário que argumentam a possibilidade legítima, legal e dentro dos preceitos constitucionais que capacitam a transação entre a Fazenda Pública e o contribuinte, constituindo-se o instituto da transação um meio de solucionar conflitos, acelerar a solução dos litígios fiscais, gera menor custo benefício para o fisco e, ainda harmonizar 
o convívio com os contribuintes (MENDONÇA, 2013, p. 140).

Importante se faz salientar as possibilidades elencadas no Código Tributário Nacional CTN; sobre as possibilidades de se suspender e extinguir o crédito tributário, para tanto, elenca-se o disposto nos artigos, 151 e 156 do CTN; a saber: Art. 151. "Suspendem a exigibilidade do crédito tributário: (...)”; Art. 156. "Extinguem o crédito tributário: III - a transação; (...)” (BRASIL, 2019).

Nesse sentido, entende-se que a transação tributária ocorrendo após a composição do crédito tributário, não necessariamente proporcionará a extinção do crédito tributário, vez que outro prazo poderá ser concedido para quitação do tributo, extinguindo-se, desta feita, o crédito tributário. Verifica-se, portanto, haverá a extinção da lide que ditará a maneira de compensação da dívida pelo contribuinte, por meio da transação tributária, que já encontra respaldo legal em diversos diplomas legislativos, como já arguido no presente estudo, incluindo o CTN (MACHADO, 2008, p. 117).

Imprescindível se faz a análise dos estágios da receita pública dos municípios, que consiste no recebimento pelo município dos tributos, multas e demais créditos a ele devidos. Tais recebimentos são efetuados pelos agentes de arrecadação, que recebem os recursos dos contribuintes e os entregam ao Tesouro Público. A arrecadação, portanto, se dá no momento em que os contribuintes comparecem perante os agentes arrecadadores a fim de liquidarem suas obrigações para com o município. Contudo, a realidade arrecadatória fiscal é deficitária, nos moldes já discutidos nesse estudo, carecendo, portanto, de estratégias na condução dos litígios tributários (JESUS, 2010, p. 14).

Percebe-se que o panorama vivenciado pelo administrador local, do município, é bastante precário relacionado aos incentivos e à eficiência na arrecadação de seus tributos. Ou seja, verifica-se grande inabilidade em âmbito local para a obtenção de impostos, isso ocorre porque os municípios possuem base tributária restrita, por negligência ou incapacidade de gestão, o que demanda grande esforço no empreendimento arrecadatório (JESUS, 2010, p. 14-15).

Com a premissa que nos diferentes âmbitos do poder público nacional, a implementação de projetos, com vistas, ao incentivo no adimplemento de tributos vem se intensificando e, possibilitando o poder público, em suas esferas, Federal, Estadual e Municipal, concederem relevantes reduções dos encargos tributários, moras e juros, incentivando os contribuintes com dívidas e obrigações fiscais pendentes efetuarem sua quitação (GODOI, 2015, p. 139).

A jurisprudência, a exemplo o Superior Tribunal de Justiça - STJ; vem entendendo e sentenciando os litígios fiscais, mantendo a primazia do interesse público, aplicando e respeitando o instituto da transação tributária, assim como, outros meios de solucionar os conflitos, na esfera de sua competência, como se descreve a seguir:

PROCESSO JUDICIAL TRIBUTÁRIO. EMBARGOS À EXECUÇÃO FISCAL. COMPENSAÇÃO TRIBUTÁRIA PRETÉRITA ALEGADA COMO MATÉRIA DE DEFESA. POSSIBILIDADE. ARTIGO 16, $\S 3^{\circ}$, DA LEF, C/C; ARTIGOS 66, DA LEI 8.383/91, 73 E 74, DA LEI 9.430/96. 1. A compensação tributária 
adquire a natureza de direito subjetivo do contribuinte (oponível em sede de embargos à execução fiscal), em havendo a concomitância de três elementos essenciais: (i) a existência de crédito tributário, como produto do ato administrativo do lançamento ou do ato-norma do contribuinte que constitui o crédito tributário; (ii) a existência de débito do fisco, como resultado: (a) de ato administrativo de invalidação do lançamento tributário, (b) de decisão administrativa, (c) de decisão judicial, ou (d) de ato do próprio administrado, quando autorizado em lei, cabendo à Administração Tributária a fiscalização e ulterior homologação do débito do fisco apurado pelo contribuinte; e (iii) a existência de lei específica, editada pelo ente competente, que autorize a compensação, ex vi do artigo 170, do CTN. 2. Deveras, o $\S 3^{\circ}$, do artigo 16, da Lei 6.830/80, proscreve, de modo expresso, a alegação do direito de compensação do contribuinte em sede de embargos do executado. 3. O advento da Lei 8.383/91 (que autorizou a compensação entre tributos da mesma espécie, sem exigir prévia autorização da Secretaria da Receita Federal) superou o aludido óbice legal, momento a partir do qual passou a ser admissível, no âmbito de embargos à execução fiscal, a alegação de extinção (parcial ou integral) do crédito tributário em razão de compensação já efetuada (encartada em crédito líquido e certo apurado pelo próprio contribuinte, como sói ser o resultante de declaração de inconstitucionalidade da exação), sem prejuízo do exercício, pela Fazenda Pública, do seu poder-dever de apurar a regularidade da operação compensatória (Precedentes do STJ: EREsp 438.396/ RS, Rel. Ministro Humberto Martins, Primeira Seção, julgado em 09.08.2006, DJ 28.08.2006; REsp 438.396/RS, Rel. Ministro José Delgado, Primeira Turma, julgado em 04.11.2008, DJe 01.12.2008). 4. A alegação da extinção da execução fiscal ou da necessidade de dedução de valores pela compensação total ou parcial, respectivamente, impõe que esta já tenha sido efetuada à época do ajuizamento do executivo fiscal, atingindo a liquidez e a certeza do título executivo, o que se dessume da interpretação conjunta dos artigos 170, do CTN, e 16, § $3^{\circ}$, da LEF, sendo certo que, ainda que se trate de execução fundada em título judicial, os embargos do devedor podem versar sobre causa extintiva da obrigação (artigo 714 VI, do CPC). 5. Ademais, há previsão expressa na Lei 8.397/92, no sentido de que: "O indeferimento da medida cautelar fiscal não obsta a que a Fazenda Pública intente ação judicial da Dívida Ativa, nem influi no julgamento desta, salvo se o juiz, no procedimento, cautelar fiscal, acolher a alegação de pagamento, de compensação, de transação, de remissão, de prescrição ou decadência, de conversão do depósito em renda, ou qualquer outra modalidade de extinção da pretensão deduzida." (artigo 15). 6. Consequentemente, a compensação efetuada pelo contribuinte, antes do ajuizamento do feito executivo, pode figurar como fundamento de defesa dos embargos à execução fiscal, a fim de ilidir a presunção de liquidez e certeza da CDA, máxime quando, à época da compensação, restaram atendidos os requisitos da existência de crédito tributário compensável, da configuração do indébito tributário, e da existência de lei específica autorizativa da citada modalidade extintiva do crédito tributário. 7. In casu, o contribuinte, em sede de embargos à execução fiscal, alegou a inexigibilidade do crédito tributário, em virtude de compensação sponte própria efetuada ante o pagamento indevido de CSSL (artigo $8^{\circ}$, da Lei 7.689/88) declarada inconstitucional pelo Supremo Tribunal Federal, tendo sido ajuizada ação ordinária para ver reconhecido seu direito à liquidação da obrigação tributária por meio da compensação efetuada. Destarte, a indevida rejeição da compensação como matéria de defesa arguível em sede de embargos à execução fiscal, conjugada ao julgamento antecipado 
da lide, resultou em prematura extinção da ação antiexacional, razão pela qual merece prosperar a pretensão recursal. 10. Recurso especial provido. Acórdão submetido ao regime do artigo 543-C, do CPC, e da Resolução STJ 08/2008 (BRASIL, 2019).

Percebe-se, portanto, que a transação tributária como meio de solução de litígios fiscais, ou seja, para a recuperação do crédito tributário já está sendo praticado pela administração pública da União, Estados e Municípios, fato estes comprovados por meio das decisões reiteradas do Poder Judiciário em suas diferentes instâncias.

Sobre a transação tributária, como método adequado de solução de litígios processuais tributários, importante se faz destacar os ensinamentos de Priscila de Mendonça (2013, p. 142):

A transação em matéria tributária não só estimula o diálogo entre os sujeitos envolvidos na relação jurídica tributária, mas também permite que a tributação se dê de forma participativa, o que por certo confere segurança, confiabilidade e também reciprocidade nas relações tributárias, as quais são complexas e nada cordiais pela visão do contribuinte. Tudo, sempre, em respeito à legalidade e a tipicidade tributárias.

Deste modo, acredita-se que o instituto da transação tributária tem o condão de aproximar as partes litigantes à autocomposição mútua e bilateral, com o objetivo de harmonizar as relações entre contribuinte e o fisco, simplificando e ajustando os resultados das demandas e processos de execução fiscal, como meio adequado para a eficiência arrecadatória no âmbito das execuções fiscais municipais, resultando por consequência na desobstrução do judiciário brasileiro, cumprindo, portanto, seu caráter primordial como método participativo de solução de controvérsias e aceleração das soluções nos conflitos de natureza tributária fiscal.

\section{CONCLUSÃO}

A União, os Estados e Municípios necessitam da geração de receitas para que possam, através do gerenciamento desses recursos, administrar a manutenção de suas esferas, para que cumpram com suas responsabilidades constitucionais perante o cidadão. Para tanto, a imposição da cobrança tributária caracteriza-se em apropriar-se dos bens dos contribuintes para atender as mencionadas necessidades do poder público. Diante do cenário apresentado, o que se observa é a elevada litigiosidade de processos de execução fiscais em todas as esferas do Poder Judiciário brasileiro, o que acarreta uma morosidade excessiva e, consequente déficit na arrecadação e na prestação jurisdicional.

O CNJ vem trazendo novas estratégias ao Poder Judiciário brasileiro, com vistas a concretizar e viabilizar o preceito constitucional de uma prestação jurisdicional efetiva e célere. Ressalta-se, ainda, a busca por estímulos para a solução dos litígios por meio extrajudicial diante do gritante número, como verificado nesse estudo, tendo o Poder Judiciário finalizado o ano de 
2017 com 80,1 milhões de processos tramitando em suas instâncias, a espera de solução.

Portanto, urge o estabelecimento de medidas que modernizem o Poder Judiciário, para que se garanta sua premissa constitucional de efetividade e celeridade, permitindo os desentraves do desenvolvimento econômico para crescimento da nação.

Nesse contexto conclui-se que a transação em matéria tributária, como método adequado de soluções de conflitos na seara dos processos de ações tributárias, constitui-se uma das medidas capazes de resolver, ou ao menos amenizar, os litígios fiscais tributários. Citado instituto da transação está fundamentado no ordenamento jurídico pátrio, permitindo a solução de forma adequada e célere dos litígios.

O Código Tributário Nacional elencou o instituto da transação tributária como forma de extinção do crédito tributário, relacionando-a no artigo 156 e regularizando-a no artigo 171. Verifica-se, contudo, que a legislação em comento não determinou a ocasião em que deve se dar a extinção, se a mesma deve ocorrer no momento da celebração da transação, ou quando do adimplemento do acordo e ressarcimento do crédito. Entende-se que a oficialização da transação revoga o crédito tributário, contudo, apenas em relação à parcela que as partes acordaram ao firmarem a transação. Conclui-se ainda que a transação tributária é compatível com obrigação do lançamento, conforme fundamenta o artigo 142, Parágrafo único, do CTN; também é conciliável com a cobrança por atividade vinculada, como disciplina o artigo $3^{\circ}$, do CTN.

Tem-se a certeza de que estímulos e iniciativas urgem ser concretizadas e difundidas para que haja efetiva reformulação do padrão litigioso tributário, iniciativas como a transação, com capacidade de melhorar e aumentar a arrecadação e por consequência desobstruir o Judiciário brasileiro. Para tanto, é imprescindível investimentos para prevenir e evitar demandas judiciais, mostrando-se imperioso empregar métodos adequados de solução de conflitos e, nesse sentido, o Poder Público tem o papel primordial de promover a redução do seu grau de litígio concordando com os êxitos dos contribuintes.

Permanecendo-se o sistema contencioso tributário brasileiro nos moldes atuais, ignorando os meios adequados consensuais que estão a sua disposição, a exemplo da transação, certamente se continuará observando um Judiciário sobrecarregado, lento, instável e permeado de incertezas e insegurança jurídica.

\section{REFERÊNCIAS}

ALBUQUERQUE, Claudiano Manoel de. Gestão de finanças públicas. 2. ed. Brasília: Coleção Gestão Pública, 2016.

ALVES, Silvio Rodrigues. O desafio do déficit público. In: LOZARDO, Ernesto (org). Déficit público brasileiro: política econômica e ajuste estrutural. Rio de Janeiro: Paz e Terra, 2017.

BRASIL. [Constituição (1988)]. Constituição da República Federativa do Brasil de 1988. 
Brasília: Presidência da República, 1988. Disponível em: http://www.planalto.gov.br/ccivil_03/ constituicao/constituicaocompilado.htm. Acesso em: 24 jul. 2019.

BRASIL. Lei $\mathbf{n}^{0}$ 5.010, de 30 de maio de 1966. Organiza a justiça federal de primeira instância, e dá outras providências. Brasília: Presidência da República, 1966. Disponível em: http://www. planalto.gov.br/ccivil_03/LEIS/L5010.htm. Acesso em: 26 jul. 2019.

BRASIL. Projeto de Lei ${ }^{\circ}$ 5.082/2009. Dispõe sobre transação tributária, nas hipóteses que especifica, altera a legislação tributária e dá outras providências. Aguardando Parecer do Relator na Comissão de Finanças e Tributação - CFT. Brasília: Presidência da República, 2009. Disponível em: https://www.camara.leg.br/proposicoesWeb/ fichadetramitacao?idProposicao=431269. Acesso em: 26 jul. 2019.

BRASIL. Superior Tribunal de Justiça. Recurso Especial: REsp 0004367-48.2005.4.03.9999 SP 2007/0275039-9. Disponível em: https://scon.stj.jus.br/SCON/jurisprudencia/toc. O+TRIBUT\%C1RIA\&repetitivos=REPETITIVOS\& $\mathrm{b}=\mathrm{ACOR} \&$ thesaurus $=$ JURIDICO\&p $=$ true . Acesso em: 29 jul. 2019.

BOLFE, Camila; SOUZA, Daniel Augusto. Política fiscal sob a ótica tributária: correntes ideológicas e o cenário brasileiro. Disponível em: http://www.apec.unesc.net/V_EEC/sessoes_ tematicas. Acesso em: 25 jul. 2019.

CAMPOS, Gustavo Caldas Guimarães de. Execução fiscal e efetividade: análise do modelo brasileiro à luz do sistema português. São Paulo: QuartierLatin, 2009. Disponível em: http:// www.mpsp.mp.br/portal/page/portal/documentacao_e_divulgacao/doc_biblioteca/bibli_servicos produtos/bibli_informativo/bibli_inf_2006/Rev-Dir-Bras. Acesso em: 23 jul. 2019.

CAMPELLO, Carlos Alberto Barreto.; MATIAS, Alberto Borges. Administração financeira municipal. São Paulo: Atlas, 2014.

CUNHA JUNIOR, Luis Arnaldo Pereira et al. IX CONGRESSO CONSAD DE GESTÃO PÚBLICA, 9., 2016, Brasília. Crise fiscal do estado brasileiro: saídas pela via da gestão. Brasília, 2016. Disponível em: http://consad.org.br/wp-content/uploads/2016/06/Painel-45-01. pdf. Acesso em: 25 jul. 2019.

CUNHA, Leonardo Carneiro da. A fazenda pública em juízo. 13. ed. Rio de Janeiro: Forense, 2016.

CONSELHO NACIONAL DE JUSTIÇA (CNJ). Justiça em números 2018: anobase 2017. Brasília: CNJ, 2018. Disponível em: http://www.cnj.jus.br/files/conteudo/ arquivo/2018/08/44b7368ec6f888b383f6c3de40c32167.pdf. Acesso em: 26 jul. 2019.

JESUS, Maria Elizabeth de. Tributação no Brasil: em busca da justiça fiscal. Rio de Janeiro: Forense, 2010.

GODOI, Marciano Seabra de. Sobre a possibilidade de a fazenda pública reverter, em juízo, decisões definitivas dos conselhos de contribuintes. São Paulo: Dialética, 2015. 
GRILLO, Fábio Artigas. Transação e a justiça tributária. 2012, 321 f. Tese (Doutorado em Direito) - Universidade Federal do Paraná, Curitiba, 2012. Disponível em: http://www. mpsp.mp.br/portal/page/portal/documentacao_e_divulgacao/doc_biblioteca/bibli_servicos_ produtos_2006/Rev-Dir-Bras_v.19_n.8.08.pdf. Acesso em: 28 jul. 2019.

MACHADO, Hugo de Brito. Transação e arbitragem no âmbito tributário. In: SARAIVA FILHO, Oswaldo O. de; GUIMARÃES, Vasco Branco (org.). Transação e arbitragem no âmbito tributário. São Paulo: São Paulo: Fórum, 2008.

MENDONÇA, Priscila Faricelli de. Transação e arbitragem nas controvérsias tributárias. 2013. 212 f. Dissertação (Mestrado em Direito) - Faculdade de Direto da Universidade de São Paulo, São Paulo, 2012. Disponível em: https://www.teses.usp.br/teses/disponiveis/2/2137/tde12022014-135619/publico/dissertacao_mestrado_final_Priscila_Faricelli_de_Mendonca.pdf. Acesso em: 28. jul. 2019.

NALINI, José Renato. Execução não é solução!. Disponível em: http://renatonalini.wordpress. com/2012/03/18/execucao-nao-e-a-solucao. Acesso em: 24 jul. 2019.

MINELLI, Daiane; GOMES, Sergio Alves. A desjudicialização e os meios alternativos de resolução de conflitos sob a égide do pós-positivismo. Revista do Direito Público, Londrina, v. 14, n. 2, p. 151-167, ago. 2019. Disponível em: http://www.uel.br/revistas/uel/index.php/ direitopub/article/view/36711. Acesso em: 13 set. 2019.

SCHERER, Tiago. Execução fiscal: novas perspectivas. Revista de Doutrina da $4^{\text {a }}$ Região. Porto Alegre, n. 64, fev. 2015. Disponível em: http://www.revistadoutrina.trf4.js.br/artigos/ edicao064/tiago_scherer.html. Acesso em: 23 jul. 2019.

ZUCCOLOTTO, Robson. RIBEIRO, Clarice Pereira de Paiva. ABRANTES, Luiz Antônio. O comportamento das finanças públicas municipais nas capitais dos estados brasileiros. In: CONGRESSO BRASILEIRO DE CUSTOS, 15., Curitiba, 2008. Anais [...]. Disponível em: http://eduem.uem.br/ojs/index.php/Enfoque/article/download/8081/4615. Acesso em: 25 jul. 2019.

Como citar: OLIVEIRA, Bruno Bastos de; BASSAN, Richard; CANTÍDIO, Cristiana Carlos do Amaral. A busca pela eficiência no âmbito das execuções fiscais municipais a a transação tributária. Revista do Direito Público, Londrina, v. 16, n. 3, p. 83-100, dez. 2021. DOI: 10.5433/24157-108104-1.2021v16n3p.83. ISSN: 1980-511X

Recebido em: 18/09/2019

Aprovado em: 24/08/2020 